\title{
Early squamous cell carcinoma of the anterior tongue; Report of two cases
}

\author{
Dr. Veeresh $\mathrm{M}^{1,}$ Dr. Kamala ${ }^{2,}$ Dr. Triveni ${ }^{3,}$ Dr. Ravikumar ${ }^{4}$ \\ ${ }^{I}$ Professor And Head, Dept. Of Dentistry, Esic Medical College \& Pgimsr, Bangalore. \\ ${ }^{2}$ Asst. Professor, Dept. Of Dentistry, Esic Medical College \& Pgimsr, Bangalore. \\ ${ }^{3,4}$ Sr. Residents, Dept. Of Dentistry, Esic Medical College \& Pgimsr,Bangalore.
}

\begin{abstract}
Squamous cell carcinoma (SCC) of anterior tongue is relatively common in India and forms a significant group of all head \& neck malignancies. Mucoepidermoid carcinoma, melanoma and adenoid cystic carcinoma are other rare tumors found in the tongue. The purpose of this article is to report two cases of early SCC of anterior tongue which were managed with wide excision. The incidence, etiology, treatment and prognosis are discussed.
\end{abstract}

Key words: Squamous cell carcinoma, early, anterior tongue.

\section{Introduction}

Squamous cell carcinoma of anterior tongue is common and accounts for $97 \%$ of all malignancies found in anterior tongue. The prediliction for males to females has been found to be $3: 1$. The peak incidence is usually in the $5^{\text {th }}$ and $6^{\text {th }}$ decades but cases have been reported in young individuals too. Carcinoma of tongue is associated frequently with alcohol and tobacco chewing as a common etiology.

The anterior tongue is a movable portion and extends from circumvallate papillae to the junction at the anterior floor of mouth. The anterior tongue is divided into four regions, tip, lateral borders and dorsal \& ventral surfaces. Lymphatic drainage from anterior aspect is into submental nodes, and the lateral borders drain into the submandibular and upper deep jugular nodes and communications which occur in the midline can lead to contralateral neck drainage.

The various treatment options for carcinoma of anterior tongue are wide excision, hemiglossectomy and primary excisions alongwith elective neck dissection. Here we show report of two cases of carcinoma of anterior tongue.

Case 1

\section{Case reports}

A 40 year old man reported to hospital with the complaint of a non healing ulcer over the tongue, since 3 months. It was initially small and it gradually progressed to present size. History revealed the habits of betel nut chewing and smoking. Clinical examination showed a ulcerative lesion in right lateral border of the anterior tongue, measuring $0.5 \mathrm{X} 2 \mathrm{~cm}$ (fig.1). Neck nodes were not palpable and on palpation of the tongue induration was there but not crossing the midline.Incisional biopsy revealed moderately differentiated squamous cell carcinoma.(fig.2) Surgery was planned as wide excision of the lesion under general anesthesia. Wide excision is done with adequate safe margins.(fig.3)Hemostasis is achieved and primary closure is done.(fig.4) The post operative recovery was uneventful. The excised lesion was sent to histopathology for assessing margins and depth of tumor extension. Histopathology report suggested that all margins are free and the depth is less than $4 \mathrm{~mm}$. Follow up has been done for 2 years and there is no sign of recurrence.

Case 2:

A 30 year old male patient reported to hospital with ulcer over the tongue since one month. Clinical examination revealed a lesion of $1 \times 1.5 \mathrm{~cm}$ in anterior tongue.(fig.5) There were no palpable lymph nodes. Incisional biopsy is suggestive of well differentiated squamous cell carcinoma of tongue.Wide excision of the lesion is done under general anesthesia. Postoperative histopathology report was suggestive of well differentiated squamous cell carcinoma, with all clear margins and tumor thickness being less than $3 \mathrm{~mm}$. Follow up has been done for 3 years. There is no report of recurrence.

\section{Discussion}

Squamous cell carcinoma of anterior tongue is relatively common in India and forms a significant group of all head \& neck malignancies. The initial evaluation of the patient with anterior tongue cancer begins with a complete history and physical examination. In addition to symptoms produced by tumor, the age and general medical condition of the patent are vital. 
The modalities of treatment vary according to the size of the lesion,location and histopathological differentiation. Carcinoma of anterior $2 / 3$ of tongue behaves differently from carcinoma of posterior $1 / 3$. The latter is more prone to be poorly differentiated and to have nodal metastasis ${ }^{1}$. An adequate, wide surgical resection will control early carcinoma of the anterior tongue. Advanced cancers of the anterior tongue, clinical stages of III and IV, should be widely excised and the cervical lymph nodes on the side of the primary lesion must be treated by surgery and radiation therapy ${ }^{2}$.

Tumors occupying anterior few centimeters of the tip of tongue have low metastatic rate, so with these tumors it is therefore best to resect malignancy widely and defer intervention in the neck. Another exception may be for superficial carcinomas, often arising in areas of preexisting leucoplakia such lesions are not necessarily small in area but, if there is no significant palpable infiltration of tongue musculature the risk of spread to cervical nodes is minimal ${ }^{3}$. Micheal J Veness et $\mathrm{al}^{4}$ concluded that elective treatment to the ipsilateral neck is not indicated in all patients with anterior tongue cancer. However for patients with tumor thickness more than $5 \mathrm{~mm}$ it is recommended that they undergo treatment to ipsilateral neck.

Hannal vargha et $\mathrm{al}^{5}$ suggested that younger patients need aggressive initial treatment and close surveillance for recurrence. In addition a diagnosis of poorly differentiated Squamous cell carcinoma on biopsy is even a stronger indication for neck dissection.

Tumour thickness is an important predictive marker for lymph node metastases. As such, it can help in decision-making with regard to management of the primary tumour and neck, a wait-and-see policy is only warranted for superficial lesions with tumour thickness of less than $7 \mathrm{~mm}^{6}$

Takahiro Asakage et. $\mathrm{al}^{7}$ revealed in their study that the patients, with stage I / II carcinoma of tongue > $4 \mathrm{~mm}$ in thickness with moderately or poorly differentiated squamous cell carcinoma have high potential for post operative cervical metastasis. Fukano et.al ${ }^{8}$ suggested that there is a discerning point at $5 \mathrm{~mm}$ of tumor depth at which cervical metastasis is probable. Electric neck therapy (surgery or irradiation) is strongly indicated for tumors exceeding $5 \mathrm{~mm}$ invasion.

The control of carcinoma of the anterior aspect of the tongue is closely related to the extent of the primary tumor and the state of the regional lymph nodes. The most important prognostic factor is the status of cervical lymph nodes. Treatment failures were most common in the cervical nodes; only $40 \%$ of patients with recurrent cervical disease could be cured. The size and differentiation of the lesion, as well as the adequacy of surgical margins, appeared to be related to regional failures. ${ }^{9}$

\section{Conclusion}

Although the size, differentiation of the lesion, as well as adequacy of surgical margins appeared to be vital in the treatment of anterior tongue cancer, the overall prognosis is unpredictable even when patients are treated following guidelines according to TNM staging. It requires a large prospective randomized multicenter study and early detection of cervical lymph node metastasis is obviously very important for improving survival.

\section{References}

[1]. Benjamin D.L. LI, G.E Ghali, Emercy A. Ninard. Cancer of the Anterior (Oral tongue).

[2]. A text book of surgical oncology.2006: 24-31.

[3]. Leipzig B, Chung CT, Johnson JT, Sagerman RH , Carcinoma of Anterior tongue.

[4]. Ann otol rhinol laryngol. 1982;(91):194-7.

[5]. H. Robert Freund, A Text book - Principles of head \& neck surgery. 151-172.

[6]. Micheal J. Veness, Garsy J. Morgan, Yasoda Sathiyaseclan and Val Gebskt. Anterior tongue cancer and the incidence of cervical lymph node metastases with increasing tumor thickness: should elective treatment to the neck be standard practice in all patients. ANZ journal of surgery. 2005;75(3): 101-105.

[7]. Hunnah varghees, karen T. Pitman, Jones T. Jhonses, lisa T. Galati. "More aggressive behavior of squamous cell carcinoma of Anterior tongue in young women".

[8]. The laryngoscope.2009;(110):123-126. Loddder WL, Teertstra HJ, Tan IB, Pameijer FA, Smeele LE, Van Velthuysen ML, van den Brekel Mw. Tumour thickness in oral cancer using an intra-oral ultrasound probe. Eur Radiol. 2011 ;21(1):98-106.

[9]. Takahiro Asakage, Tomoyuki yokose, kigoshi mukeri, shoichiro, Tsugane, Masao Asui satoshi eblhan. Tumor thickness predicts cervical metastasis in patients with stage I/II carcinoma of the tongue.CANCER 1982:1443-8.

[10]. Fukano H, Matsuura H, Hasegawa Y, Nakamura S. Depth of invasion as a predictive factor for cervical lymph node metastasis in tongue carcinoma. Head Neck.1997;19(3):205-10.

[11]. Johnson JT, Leipzig B, Cumming CW. Management of $\mathrm{T}_{1}$ carcinoma of the Anterior aspect of the tongue. Arch of otolaryngol.1980;106(5): 249-251. 
Fig.1 Case 1. Preoperative

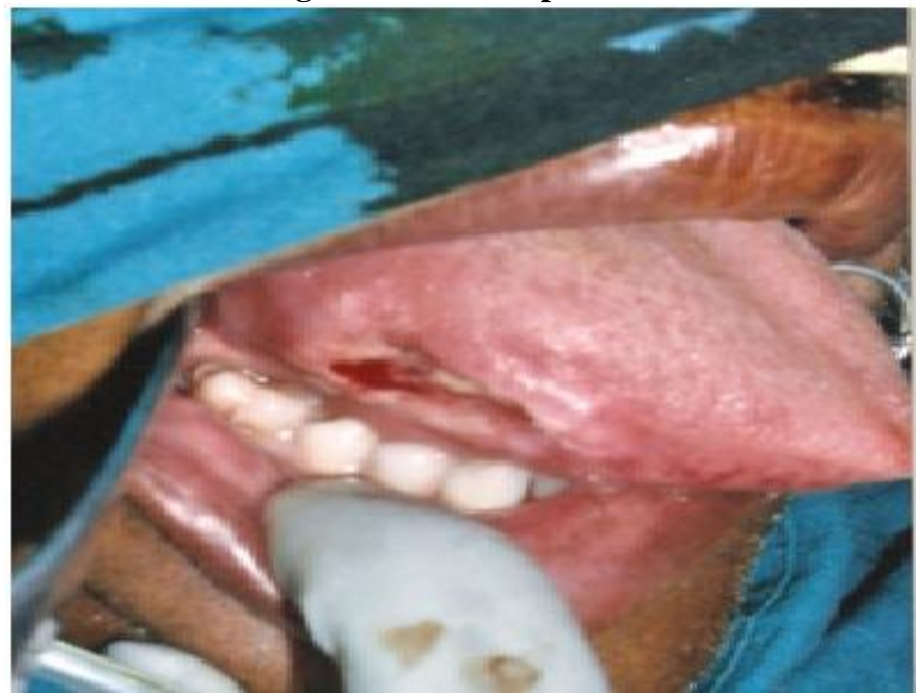

Fig.2 Histopathologic Picture

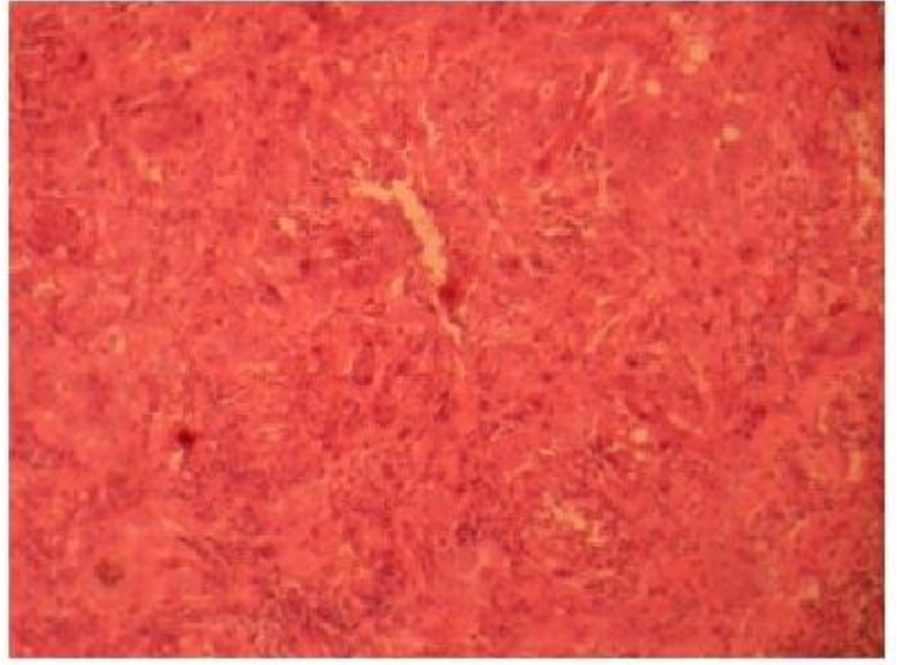

Fig.3 Post Exicision Of The Lesion

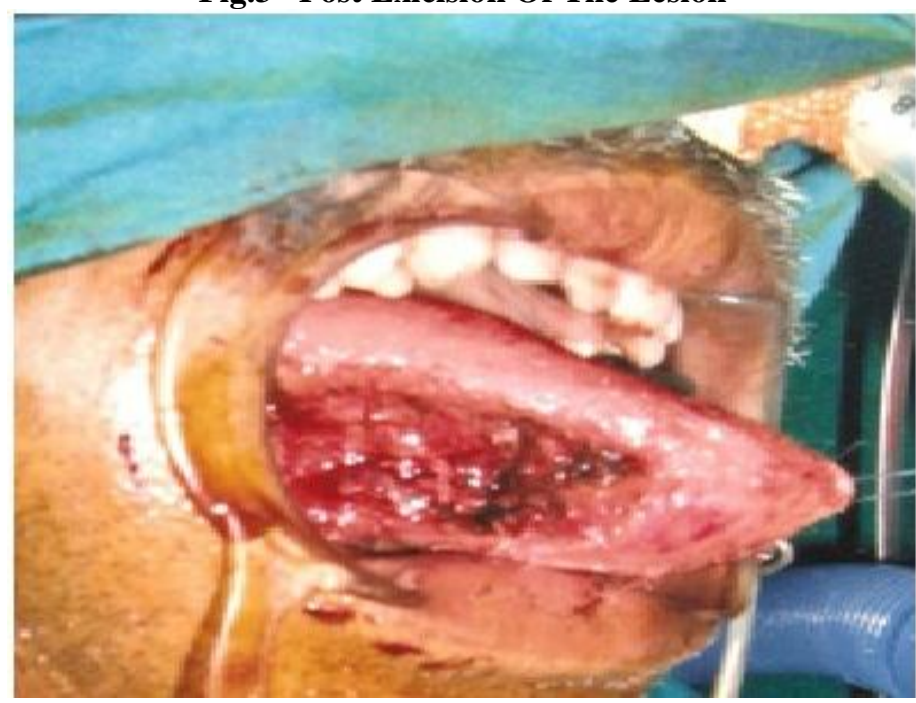


Fig.4 After Primary Closure

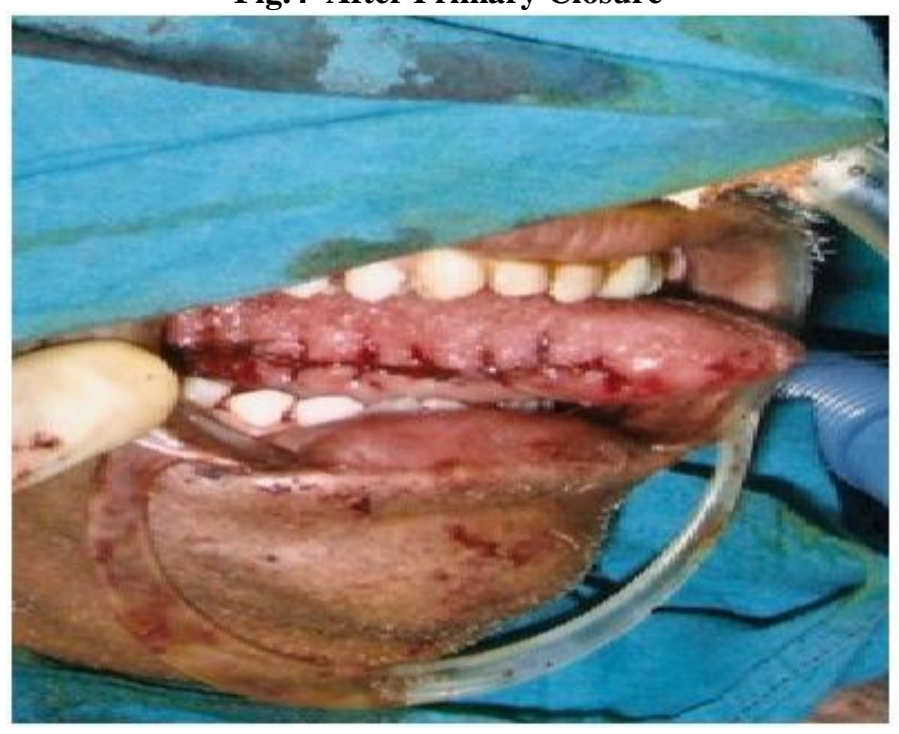

Fig.5 Case 2 Preoperative.

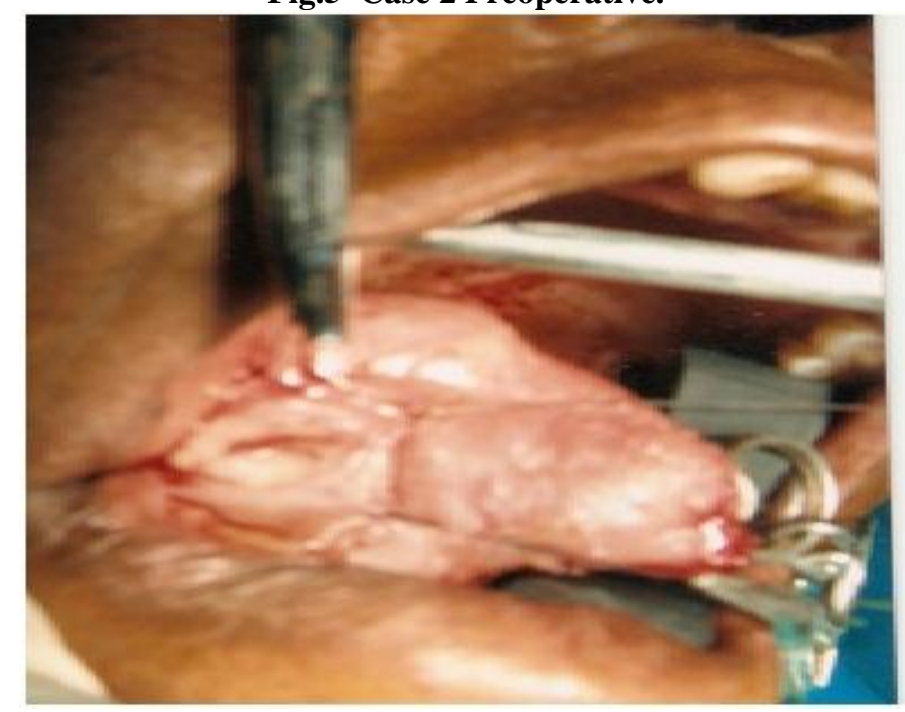

